\title{
What Is New in the Understanding of Non Healing Wounds Epidemiology, Pathophysiology, and Therapies
}

\author{
H. Trøstrup, ${ }^{1}$ T. Bjarnsholt, ${ }^{1,2}$ K. Kirketerp-Møller, ${ }^{3}$ N. Høiby, ${ }^{1,2}$ and C. Moser ${ }^{1}$ \\ ${ }^{1}$ Department of Clinical Microbiology 9301, Juliane Mariesvej 22, Copenhagen University Hospital, DK-2100 Copenhagen, Denmark \\ ${ }^{2}$ Department of International Health, Immunology, and Microbiology, Faculty of Health Sciences, University of Copenhagen, \\ DK-2200 Copenhagen, Denmark \\ ${ }^{3}$ Department of Orthopedic Surgery, Hvidovre University Hospital, DK-2650 Copenhagen, Denmark
}

Correspondence should be addressed to T. Bjarnsholt; tbjarnsholt@sund.ku.dk and C. Moser; moser@dadlnet.dk

Received 20 November 2012; Accepted 9 April 2013

Academic Editor: Marisa Herson

Copyright (C) 2013 H. Trøstrup et al. This is an open access article distributed under the Creative Commons Attribution License, which permits unrestricted use, distribution, and reproduction in any medium, provided the original work is properly cited.

\begin{abstract}
Chronic wounds are a growing socioeconomic problem in the western world. Knowledge on recalcitrant wounds relies on in vitro studies or clinical observations, and there is emerging evidence on the clinical impact of bacterial biofilm on skin healing. Chronic wounds are locked in the inflammatory state of wound healing, and there are multiple explanations for this arrest with the theory of exaggerated proteolysis as the most commonly accepted. Previously, there has not been enough focus on the different etiologies of chronic wounds compared to acute, healing wounds. There is an urgent need to group chronic wounds by its cause when searching for possible diagnostic or therapeutic targets. Good wound management should therefore consist of recognition of basic wound etiology, irrigation, and debridement in order to reduce microbial and necrotic load, frequently changed dressings, and appropriate antimicrobial and antibiofilm strategies based on precise diagnosis. Representative sampling is required for diagnosis and antimicrobial treatment of wounds. The present review aims at describing the impact of biofilm infections on wounds in relation to diagnosing, treatment strategies, including experimentally adjuvant approaches and animal models.
\end{abstract}

\section{Introduction}

A practical classification of a nonhealing wound is one that fails to heal spontaneously within 3 months [1]. Emergence of chronic wounds is a substantial health problem as $1 \%$ of western population will suffer from it. Common chronic types of wounds are venous leg ulcers, ischemic wounds, diabetic foot ulcers, and pressure wounds [2].

Socioeconomically, management of chronic wounds reaches a total cost of $2-4 \%$ of the health budget in western countries [3]. This estimate is expected to rise as a natural consequence of an increasing population of the elderly and the diabetic and obesity epidemic. Complications to nonhealing wounds are vast, and patients are at risk of severe pain, septicaemia, hospitalization, and in some cases amputations.

Microbiological findings in chronic wounds vary depending on the mode of sampling (swab versus biopsies) and the diagnostic method used (culturing, PCR methods, and microscopy preceded by PNA-FISH). The most common bacteriological findings in human chronic wounds are also present on the skin, in faeces and water: Staphylococcus aureus (SA), coagulase-negative staphylococci, Enterococcus faecalis, Proteus species, anaerobic bacteria, and Pseudomonas aeruginosa (PA) [4].

All the studies of chronic wounds so far agree on the almost universal presence of SA [5-8]. Also, most studies agree on the PA being present in around half of the investigated wounds and that the deep dermal tissues of all chronic wounds harbor multiple bacterial species $[4,5,9]$. The organization and distribution of these two species in the chronic wound bed has been elucidated by two studies $[9,10]$. Two specific PNA probes for FISH analysis, one for SA and one for PA in combination with a universal bacterial probe, were used in both. The observations revealed that the different bacterial species might be present in the same wound but they seemed not to mix. Very few aggregates of different bacteria were observed in close proximity of each other. Aggregates of mixed species were observed by James et al. [6], 
TABLE 1: Predisposing factors for developing a chronic wound.

\begin{tabular}{l}
\hline Age \\
Venous insufficiency \\
Arterial insufficiency \\
Diabetes \\
Neuropathy \\
Renal impairment \\
Systemic morbidity (fibrosis, atherosclerosis, edema, sickle cell \\
disease) \\
Malignancy \\
Lymphoedema \\
Trauma \\
Rheumatological morbidity \\
Malnutrition \\
Pressure over prominent bone \\
Use of corticosteroids \\
Vasculitis \\
Immune suppression \\
Pyoderma gangrenosum
\end{tabular}

with both rod- and cocci-shaped bacteria in close proximity to one wound.

Growing evidence supports that chronic wounds can be attributed to an adversely combination of structural damage and establishment of a chronic biofilm infection, inducing host responses, further structural damage, and thereby generation of a vicious circle $[6,9,11,12]$.

A critical review of current literature on wound management is needed considering the increasing evidence of bacteria being present as biofilms resistant to antibiotics and the defense mechanisms of the host.

\section{Pathophysiologies of Wounds}

Wound healing is comprised of a series of complex events with different time spans, which are not fully understood. Different pathogenetic mechanisms cause the establishment and maintenance of nonhealing wounds and may explain the divergence in existing literature on chronic wounds. Compromised venous flow, atherosclerosis, age, diabetes, renal impairment, lymphoedema, rheumatological disease, poor nutritional status, local pressure over prominent bone, and ischemia-refusion injury as a result of trauma are all possible causes of chronic wounds (Table 1). Most of such wounds have more than one microbial etiology, and this has to be taken in consideration in the clinical care.

In order to optimize treatment the pathogenesis has to be illuminated for each different category of wound. Unfortunately, we have no knowledge on the differences or similarities in different categories of chronic wounds as most of the previous literature compares chronic wounds of different microbial etiologies to healing wounds.
In normal skin wound healing is divided into four spatial and temporal integrated phases which occur in a tight regulated modus: hemostasis following a structural damage to the skin, inflammation, proliferation, and tissue remodeling [13].

Angiogenesis and proliferation of endothelial cells and granulation tissue are stimulated by local cytokines like IL$1 \beta$, IL- 8 , and TNF- $\alpha$ and will in normal wound healing follow the proteolysis of a temporary wound matrix.

Chronic wounds are thought to persist in the inflammatory state of wound healing [14]. The theory of exaggerated proteolysis in wound fluids from patients with chronic venous ulcers is also dominating $[15,16]$. The current understanding is that locally elevated levels of proteolytic enzymes in the hypoxic microenvironment of the wound bed degrade beneficial growth factors and thereby prevent the wound from progressing into the proliferative phase with laying of granulation tissue and a provisional matrix as a precursor for tissue remodelling and healing.

Histologically, chronic wounds are infiltrated by $\mathrm{T}$ cells and macrophages in the dermis, and this causes a cascade of tissue toxicity or local oxidative stress caused by cytokines, proteases, and free oxygen radicals of leucocyte [17]. Bacteria may also play a role in immunoregulation locally [18].

The prolongated inflammation is possibly also induced by local biofilm infection, which causes upregulated cytokines and reduced growth factors. In humans the loss of skin barrier as a consequence of a structural damage to the skin will cause microorganisms to colonize the damaged area and successive formation of biofilm. This transformation from planktonic to biofilm mode of growth in vivo is not fully understood. From in vitro studies using type strains various physiological changes and mutations have been shown to be involved, all depending on the species and the experimental set up. It has also been shown that this is a dynamic process, where biofilm growing bacteria can reverse in to the planktonic mode of growth to leave the biofilm probably due to lack of nutrients, a so-called dispersion. Whether this is possible in the wound bed is not know. Biofilms can be formed by virtually all kinds of bacteria and fungi including commonly found PA and SA in nonhealing wounds [4]. Ex vivo studies show that bacterial aggregates are surrounded by debris, pus, and inflammatory cells (Figure 1). The biofilms in chronic wounds do not possess the highly structured organization that has been described for in vitro biofilms, but they resist antibiotics and the host defense nevertheless $[12,19,20]$. The background for this transformation to biofilm mode of growth is believed to be survival mechanisms of the microorganisms, and in vivo this is due to evasion of the host responses [21]. The result is adaptation to the chronic phenotype, which is the biofilm lifestyle, in contrast to the acute phenotype, which is the planktonic lifestyle. The former is also found in other chronic infections [22].

In the last decade there has been a focus on bacteria and their role in promoting a continuous inflammatory response probably adding to the tissue damage and preventing wound healing [12]. This is especially a problem since when the biofilm has established, it enables the bacteria to resist antibiotics and other antimicrobial agents such as silver and the host 


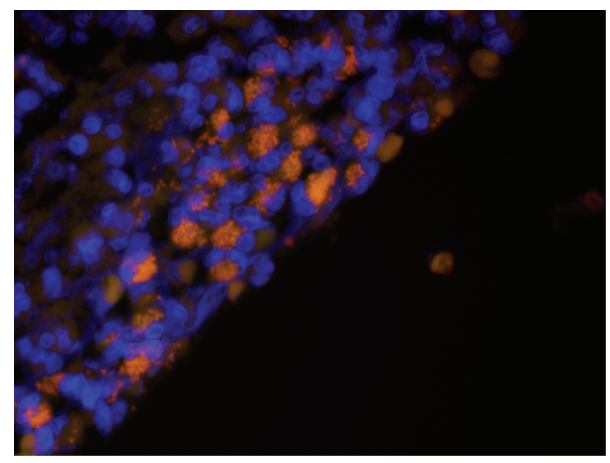

FIGURE 1: Biopsy showing numerous biofilm aggregates of PA (identified by a specific PNA FISH probe (red stain)) surrounded by host cells (DAPI (bluestain)), in a chronic nonhealing wound (magnification $\times 1000$ ).

defense. The biofilm resists antibiotic concentrations 1000 times higher than the planktonic counterpart [23-26]. This implicates that if the bacteria succeed in forming a biofilm in the wound bed, they will be extremely difficult to eradicate. In a study by Kirketerp-Møller et al. [9] chronic wounds samples obtained from 22 different patients, all allegedly infected by PA, were investigated. These wound samples were investigated by both standard culturing methods and peptide nucleic acid-based fluorescence in situ hybridization (PNAFISH) for direct identification of bacteria. By means of the classic culturing methods, SA was detected in the majority of the wounds, whereas PA was in only 2. In contrast, by visualizing the bacteria using PNA-FISH, it was observed that a large fraction of the wounds in fact harbored PA. The visual observations revealed the structural organization of bacteria in the samples. It appeared that PA was aggregated and imbedded in the matrix component alginate. The matrix is one of the hallmarks of the biofilm mode of growth. The biofilms of PA were detected in the wound bed, whereas SA biofilms, when present, were detected on the surface of the wounds. This is supported by other observations demonstrating that SA appears in biofilms on the surface of the wound bed [9]. In the study by James et al. [6], an elevated presence of microbial aggregates in chronic wounds compared to acute wounds by usage of scanning electron microscopy (SEM) was observed.

There is now evidence that bacteria, and especially PA biofilm, contribute to the lack of healing in recalcitrant wounds $[4,9,27]$, and research in animal models of chronic PA biofilm infections in wounds supports these findings [28, 29]. In a chronic wound model PA biofilms kept the wounds in a polymorphonuclear (PMN) dominated inflammatory state (Trøstrup, Thomsen et al., WRR, resubmitted, 2012).

In the biofilms the aggregates of bacteria are embedded in an extracellular matrix consisting of proteins, polysaccharides, and extracellular DNA (eDNA). Especially the eDNA can be the source of exchange of antibiotic resistance caused by mutations in target genes. It is known that the biofilm phenotype promotes higher mutation rates than when the bacteria are in the planktonic phenotype [30]. Another characteristic of biofilms is slow growth of the bacteria and the so-called persisters which are highly resistant to antibiotics [31]. Both the matrix and the slow growth are believed to be major contributors to the increased tolerance to antibiotics, disinfectants and host responses [32].

In order to understand the pathogenesis of a given type of wounds, patient populations have to be comparable regarding comorbidity and age and their wounds and the microbial species in the wounds also have to be comparable.

Collection of wound fluids followed by careful analysis in all categories of patients is an easy and noninvasive means to obtain knowledge of the cellular microenvironment of wounds. The composition of wound fluid reflects the temporal processes taking place in the tissue of a wound. A standardized method to collect and examine the protein content in chronic wound fluids is needed [33].

In 2011 we compared wound fluids from chronic venous ulcers collected and standardized over a time period of 4 weeks, to fluids from acute, open granulating wounds in order to map the differences in proteins of interest. We expected to find elevated levels of proteinases in the chronic wound fluids (CWF) compared to the acute (AWF) in accordance with the current paradigm claiming an excessive proteolytic local environment in chronic ulcers $[34,35]$ resulting in degradation of extracellular molecules like fibronectin and growth factors locally [36, 37]. Surprisingly, we found no significant different levels of neither proteolytic nor proinflammatory, proangiogenic, growth factor or antimicrobial peptides in the two compared groups. As expected, we found histologically a surplus of mononuclear cells in the chronic wound edges. The only protein quantitatively differing between chronic and healing wounds was increased S100A8/A9 in the latter [38]. S100A8/A9 is a proinflammatory neutrophilic derived heterodimer involved in cell proliferation, redox reaction, and wound healing $[38,39]$.

Previously, we also found that in chronic venous ulcers, the duration of wound fluid collection influences levels of IL$1 \beta$, IL- $1 \alpha$, and IL-8. Cytokine levels increase with collection time, but surprisingly, the longer the collection time, the lesser the ability to stimulate human dermal fibroblasts [40]. Clinically, the nonproliferative property of $24 \mathrm{~h}$ wound fluids may have important consequences for practical wound fluid management [41]. For example a beneficial effect of irrigation could be explained by the continuous removal of deleterious wound fluid factors [42]. Besides the intrinsic factors, local wound environment is loaded with PMNs and their toxic oxygen radicals and degrading enzymes as a result of the persisting inflammation, and these may also participate in the maintenance of the wound in a chronic state $[43,44]$.

There is an urgent need for identifying possible target molecules for diagnostic or prognostic markers of healing. As for pressure ulcers, proteomic technology has recently been used on wound fluids for detection of the content of multiple proteins centrally and in the periphery of such ulcers compared to healing ulcers. Twenty-one proteins were found to distinguish between healed and chronic wounds, and 19 proteins were differentially expressed between the interior and periphery of wounds [45]. 


\section{Therapies}

Individual Design of Therapy Based on the Individual Pathophysiology. Randomized clinical trials of optimal treatment of wound healing are scarce $[46,47]$ presumably because of the heterogeneity and multimorbidity of these patients [48]. Every category of wound has its own standard multimodal and multidisciplinary treatment regime with local and systemic treatment. Clinically, the emergence of granulation tissue is the criteria of success of managing chronic wounds. Other criteria for wound healing include decrease in size or complete reepithelialization. There are no systemic or other local markers of healing that currently are used in clinical practice for diagnosis or evaluation of treatment response to treatment.

Compression therapy, surgical debridement, antibiotic treatment when there are clinical signs of infection and maintenance of a moist wound environment are all cornerstones in venous leg ulcer therapy. Skin grafting of chronic venous ulcers improves healing rate [49] unless there is chronic PA infection locally at the time of surgery [27]. A bioengineered skin equivalent also seems effective [50]. Surgical correction of superficial venous reflux in addition to compression bandaging did not improve ulcer healing in a controlled, randomized clinical trial, though it may reduce the recurrence of venous leg wounds [51].

Standard of care for diabetic foot ulcers includes offloading, attentive debridement, maintenance of a moist wound environment, and, if infection is present, systemic antibiotics. As for the risk of amputation in diabetic patients with wounds, this was reduced both by the use of hyperbaric oxygen therapy (HBOT) [52] and adjuvant topical treatment with granulocyte-stimulating factor (G-CSF). Unfortunately, however, no beneficial effect on healing was found by the use of G-CSF in these patients [53]. Maggot therapy may be an alternative to surgical debridement, especially in diabetic foot ulcers $[54,55]$.

As for pressure ulcers, standard treatment consists of pressure relief, enzymatic and surgical debridement, maintenance of a clean, moist wound environment, and in some cases osteotomy. Monitoring and optimizing the nutritional status of unconscious or paralysed patients are also of critical importance.

Ischemic wounds are caused by arterial insufficiency and are often very painful. Standard treatment regime is vascular surgery to restore circulation (if possible), good pain control and moist dressings on open wounds, and no debridement unless there is an active infection. Dressings containing antimicrobial or pain relieving substances used beneath compression bandages are currently being developed [56] and are typically used for chronic wounds of vascular origin. No significant difference in healing rates was found when comparing different types of dressings beneath appropriate compression bandages in a Cochrane study, where the authors compared hydrocolloids, foam dressings, alginates, low-adherent dressings, and hydrogels [57].

Topical silver or silver dressings are used in infected wounds of all origins, but evidence for their efficacy is lacking [58], and this is probably due to different microbial etiologies.
Application of topical growth factors is an adjuvant to standard care of treatment to nonhealing wounds. Depletion of growth factors shows delayed wound healing rate in vitro, but unfortunately substitution of single growth factors shows disappointing results in daily clinical practice. For example, topical application of recombinant basic fibroblast growth factor (FGF) has no advantage over placebo in healing potential of chronic neuropathic diabetic ulcers of the foot [59]. Topical application of epidermal growth factor (EGF) to nonhealing venous ulcers did not promote reepiteliazation [60]. The latter may be due to the degradation of EGF and PDGF in the extracellular matrix [61], since this degradation was reversed when applying matrix metalloproteinase inhibitors in chronic ulcers; however, clinical studies must take the current state of the particular wound treated in to consideration. Furthermore, physicians must be sure that the amount of growth factor and treatment duration is sufficient to produce a biologic response [62]. Assessment tools for these matters unfortunately do not exist.

An experimental tool used in combination with standard wound care, topically applied working platelet concentrate or plasma (PRP), may be used to boost chronic inflammatory wounds into the state of proliferation and healing as they release multiple growth factors and cytokines into the wound mimicking natural healing conditions $[63,64]$. In addition, PRP shows antimicrobial activity towards Escherichia coli and SA, but not PA [65]. Recombinant platelet-derived growth factor (Regranex) is currently the only approved exogenously applicable drug for chronic wounds, showing promising results in wound healing of diabetic foot ulcers [66]. With respect to the microbial etiology, it is important to reduce local biofilm load locally in the wound for optimal healing [67].

Regarding an autologous platelet-rich fibrin patch, promising results exist as it increases formation of granulation tissue in a heterogenic group of problem wounds; however, further randomized and controlled studies are needed [68]. In a prospective trial, complete closure was observed in $66.7 \%$ of patients with venous leg ulcers in 7.1 weeks with an average of two applications of autologous platelet-rich fibrin matrix membrane per patient [69]. However, one randomized prospective double-blind placebo-controlled study (1991) investigated the use of autologous plateletderived wound healing formula and did not find significantly improved healing in the patients with lower extremity wounds of predominantly diabetic origin [70].

There are multiple emerging trends in the management of the different categories of chronic wounds. Currently, there is a focus on stem cell therapy in treatment of problem wounds [71]. A recent publication showed improved wound healing, neovascularization, and endothelial progenitor cell recruitment in a murine diabetic wound model [72]. No gain in reepithelialization was, however, found in treating cutaneous lesions of diabetic mice with combination of PRP and autologous mesenchymal stem cell transplant versus PRP alone [73].

Negative pressure therapy with devices absorbing detrimental exudates and transudates and promoting vascularization may reduce surface area in some kind of wounds [74-76]. 
Low-frequency ultrasound (US) has been used clinically for many years in order to promote healing; however, its efficacy remains to be proven. Cullum et al. report no evidence of a benefit associated with low-frequency US in chronic venous leg ulcers [77], but others find a possible positive effect of US on wound area in the same category of patients [78].

There is no current clear evidence of laser therapy and improvement of wound healing [79].

As evident from the previously mentioned no single treatment or handling of chronic wounds has been convincing. An important reason for the unsuccessful management of chronic wounds is missing consideration of biofilm physiology in the antibiotic and previously mentioned treatments of chronic wounds. Apart from increased demands to sampling and analysis as stated previously, treatment of biofilms has to include knowledge of the background for the tolerance of biofilms.

Anwar and Costerton were among the first to report an up to 1000 -fold increased minimal inhibitory concentrations (MICs) of biofilm growing PA as compared to planktonic growing PA [80]. Instead of using traditional diffusion testing of antibiotic susceptibility, biofilm resistance testing has revealed significantly increased MICs of several antibiotics [81-83]. Recent in vivo studies on PK/PD dynamics when treating biofilm infections have revealed that biofilm growing bacteria in general follows the same PK/PD parameters (time-, concentration-, or area-under-the-curve-dependent killing) as planktonic growing bacteria when analyzing outcome of antibiotic treatment [84]. However, an interesting observation was an element of concentration-dependent killing of biofilm growing PA of beta-lactam treatment probably due to high MICs and a concentration gradient in the biofilms [84]. Moreover, a time dependent killing element was observed in the treatments with colistin [84]. Thus the parameter best correlating to elimination of biofilm growing PA in the lungs was the area under the curve (AUC) versus the minimal biofilm inhibitory concentration (MBIC) [84].

However, the consequence of these observations is that nonobtainable concentrations (due to toxicity) of antibiotics are necessary to eradicate the biofilms. This augments the difficulties for many antibiotics to penetrate into poorly vascularized tissue of many patients with chronic wounds.

Experience of treating biofilm related infections is particularly obtained from handling chronic lung infections in cystic fibrosis patients, periprosthetic joint infections, and colonization of tunnelated central venous catheters. A possible solution is to combine several different treatment strategies, both antibiotic and non-antibiotics strategies. Some of the latter, for example, the surgical debridement to remove dead and infected tissue has been mentioned above. Concerning antibiotic use of high doses, long-term combination therapy with two (or more-especially in cases of multiple-species biofilms) antibiotics with different mode of action is now a well-established strategy [85-87]. Hereby different physiological niches of the biofilm are reached and development of antibiotic resistance is prevented [87-89]. Antibiotics penetrating well into the tissue have to be selected.

Another used strategy is adding local antibiotic treatment achieving higher antibiotic concentrations at the site of infection [87]. This mode of administration is especially used in patients with cystic fibrosis, where inhalation of antibiotics like colistine tobramycin, and aztreonam is now available in special formulations. Likewise, local application of antibiotics during treatment of periprosthetic joint infections is routine practice at some institutions [85]. Local treatments can also be agents not suitable for systemic use as mentioned previously. Finally, adding of quorum sensing inhibiting agents like macrolides in cystic fibrosis can be considered.

All experiences, both in vitro and in vivo, report significantly improved effect of antibiofilm treatments if these are initiated early and on young biofilms. In contrast, older more established biofilms, which may also have resulted in substantial tissue degradation, are more difficult to treat. Even though implementation of these antibiofilm strategies hopefully can improve outcomes of chronic wounds for many patients, some may remain infected. In these patients where the biofilms cannot be eradicated completely the strategy by means of suppression therapy with antibiotics may be an option and is used in several cystic fibrosis centers, as opposed to only treating patients when they are experiencing exacerbations. Based on accurate microbial sampling and diagnosing in cystic fibrosis, this approach is used by inhalation of antibiotics (especially colistin) alternating with routine intravenous antibiotic courses every three months to reduce bacterial load and thereby the biofilm induced inflammation [87]. Utilizing information and experiences from handling biofilm infections in one host niche probably can be translated to other host niches such as chronic wounds. The exact composition of the treatments modified to chronic wounds has to be established based on trials and records of the outcomes and animal experiments.

\section{Conclusion}

Chronic nonhealing wounds remain to be a clinical challenge with room for improvements. The increasing recognition that different categories of wounds have to be regarded and handled diversely is a big step forward in the treatment of chronic wounds. Hopefully our growing understanding of the complex bacteriology of chronic wounds will result in optimized treatment regimes. Involvement of representative animal models is a promising approach where the numerous bewildering factors can be compensated for.

Including the impact of biofilm infections with its chronic induction of the host responses in handling of nonhealing wounds is an auspicious area. Especially this kind of infection demands particular antibiotic treatment strategies, like higher doses and combination of antibiotics. In addition, antibiotic penetration in the skin is somewhat unpredictable, especially if blood circulation is comprised. Finally, more alternative antibiofilm strategies may be implemented in chronic wound care as has been suggested for other chronic biofilm infections $[85,90,91]$.

With the enhanced knowledge larger, clinical and randomized trials may be more attractive to perform in order to evaluate the different treatments for the benefit of this increasingly large group of patients. 


\section{References}

[1] A. E. Saltmarche, "Low level laser therapy for healing acute and chronic wounds-the extendicare experience," International Wound Journal, vol. 5, no. 2, pp. 351-360, 2008.

[2] M. Bitsch, I. Laursen, A. M. Engel et al., "Epidemiology of chronic wound patients and relation to serum levels of mannanbinding lectin," Acta Dermato-Venereologica, vol. 89, no. 6, pp. 607-611, 2009.

[3] F. Gottrup, "Optimizing wound treatment through health care structuring and professional education," Wound Repair and Regeneration, vol. 12, no. 2, pp. 129-133, 2004.

[4] K. Gjødsbøl, J. J. Christensen, T. Karlsmark, B. Jørgensen, B. M. Klein, and K. A. Krogfelt, "Multiple bacterial species reside in chronic wounds: a longitudinal study," International Wound Journal, vol. 3, no. 3, pp. 225-231, 2006.

[5] T. R. Thomsen, M. S. Aasholm, V. B. Rudkjøbing et al., "The bacteriology of chronic venous leg ulcer examined by culture-independent molecular methods," Wound Repair and Regeneration, vol. 18, no. 1, pp. 38-49, 2010.

[6] G. A. James, E. Swogger, R. Wolcott et al., "Biofilms in chronic wounds," Wound Repair and Regeneration, vol. 16, no. 1, pp. 3744, 2008.

[7] S. E. Dowd, Y. Sun, P. R. Secor et al., "Survey of bacterial diversity in chronic wounds using Pyrosequencing, DGGE, and full ribosome shotgun sequencing," BMC Microbiology, vol. 8, article 43, 2008.

[8] R. D. Wolcott, V. Gontcharova, Y. Sun, and S. E. Dowd, "Evaluation of the bacterial diversity among and within individual venous leg ulcers using bacterial tag-encoded FLX and Titanium amplicon pyrosequencing and metagenomic approaches," BMC Microbiology, vol. 9, article 226, 2009.

[9] K. Kirketerp-Møller, P. Ø. Jensen, M. Fazli et al., "Distribution, organization, and ecology of bacteria in chronic wounds," Journal of Clinical Microbiology, vol. 46, no. 8, pp. 2717-2722, 2008.

[10] M. Fazli, T. Bjarnsholt, K. Kirketerp-Møller et al., "Nonrandom distribution of Pseudomonas aeruginosa and Staphylococcus aureus in chronic wounds," Journal of Clinical Microbiology, vol. 47, no. 12, pp. 4084-4089, 2009.

[11] S. C. Davis, C. Ricotti, A. Cazzaniga, E. Welsh, W. H. Eaglstein, and P. M. Mertz, "Microscopic and physiologic evidence for biofilm-associated wound colonization in vivo," Wound Repair and Regeneration, vol. 16, no. 1, pp. 23-29, 2008.

[12] T. Bjarnsholt, K. Kirketerp-Møller, P. Ø. Jensen et al., "Why chronic wounds will not heal: a novel hypothesis," Wound Repair and Regeneration, vol. 16, no. 1, pp. 2-10, 2008.

[13] W. K. Stadelmann, A. G. Digenis, and G. R. Tobin, "Physiology and healing dynamics of chronic cutaneous wounds," American Journal of Surgery, vol. 176, no. 2A, supplement, pp. 26S-38S, 1998.

[14] S. L. Drinkwater, A. Smith, and K. G. Burnand, "What can wound fluids tell us about the venous ulcer microenvironment?" The International Journal of Lower Extremity Wounds, vol. 1, no. 3, pp. 184-190, 2002.

[15] A. N. Moor, D. J. Vachon, and L. J. Gould, "Proteolytic activity in wound fluids and tissues derived from chronic venous leg ulcers," Wound Repair and Regeneration, vol. 17, no. 6, pp. 832839, 2009.

[16] N. J. Trengove, M. C. Stacey, S. Macauley et al., "Analysis of the acute and chronic wound environments: the role of proteases and their inhibitors," Wound Repair and Regeneration, vol. 7, no. 6, pp. 442-452, 1999.

[17] M. Wlaschek and K. Scharffetter-Kochanek, "Oxidative stress in chronic venous leg ulcers," Wound Repair and Regeneration, vol. 13, no. 5, pp. 452-461, 2005.

[18] S. G. Jones, R. Edwards, and D. W. Thomas, "Inflammation and wound healing: the role of bacteria in the immuno-regulation of wound healing," The International Journal of Lower Extremity Wounds, vol. 3, no. 4, pp. 201-208, 2004.

[19] T. Bjarnsholt, T. Tolker-Nielsen, M. Givskov, M. Janssen, and L. H. Christensen, "Detection of bacteria by fluorescence in situ hybridization in culture-negative soft tissue filler lesions," Dermatologic Surgery, vol. 35, no. 2, supplement, pp. 1620-1623, 2009.

[20] S. Fexby, T. Bjarnsholt, P. Ø. Jensen et al., "Biological trojan horse: antigen 43 provides specific bacterial uptake and survival in human neutrophils," Infection and Immunity, vol. 75, no. 1, pp. 30-34, 2007.

[21] A. Filloux and I. Vallet, "Biofilm: positioning and organisation of bacterial communities," Medecine/Sciences, vol. 19, no. 1, pp. 77-83, 2003.

[22] L. Yang, L. Jelsbak, R. L. Marvig et al., "Evolutionary dynamics of bacteria in a human host environment," Proceedings of the National Academy of Sciences of the United States of America, vol. 108, no. 18, pp. 7481-7486, 2011.

[23] L. Hall-Stoodley, J. W. Costerton, and P. Stoodley, "Bacterial biofilms: from the natural environment to infectious diseases," Nature Reviews Microbiology, vol. 2, no. 2, pp. 95-108, 2004.

[24] W. Costerton, R. Veeh, M. Shirtliff, M. Pasmore, C. Post, and G. Ehrlich, "The application of biofilm science to the study and control of chronic bacterial infections," Journal of Clinical Investigation, vol. 112, no. 10, pp. 1466-1477, 2003.

[25] M. Alhede, K. N. Kragh, K. Qvortrup et al., "Phenotypes of nonattached Pseudomonas aeruginosa aggregates resemble surface attached biofilm," PloS One, vol. 6, no. 11, Article ID e27943, 2011.

[26] M. Burmølle, T. R. Thomsen, M. Fazli et al., "Biofilms in chronic infections-a matter of opportunity-monospecies biofilms in multispecies infections," FEMS Immunology and Medical Microbiology, vol. 59, no. 3, pp. 324-336, 2010.

[27] T. Høgsberg, T. Bjarnsholt, J. S. Thomsen, and K. KirketerpMøller, "Success rate of split-thickness skin grafting of chronic venous leg ulcers depends on the presence of Pseudomonas aeruginosa: a retrospective study," PLoS ONE, vol. 6, no. 5, Article ID e20492, 2011.

[28] G. Zhao, P. C. Hochwalt, M. L. Usui et al., "Delayed wound healing in diabetic (db/db) mice with Pseudomonas aeruginosa biofilm challenge: a model for the study of chronic wounds," Wound Repair and Regeneration, vol. 18, no. 5, pp. 467-477, 2010.

[29] A. K. Seth, M. R. Geringer, A. N. Gurjala et al., "Treatment of Pseudomonas aeruginosa biofilm-infected wounds with clinical wound care strategies: a quantitative study using an in vivo rabbit ear model," Plastic and Reconstructive Surgery, vol. 129, no. 2, pp. 262e-274e, 2012.

[30] T. C. R. Conibear, S. L. Collins, and J. S. Webb, "Role of mutation in Pseudomonas aeruginosa biofilm development," PLoS ONE, vol. 4, no. 7, Article ID e6289, 2009.

[31] K. Lewis, "Persister cells," Annual Review of Microbiology, vol. 64, pp. 357-372, 2010.

[32] J. W. Costerton, Z. Lewandowski, D. E. Caldwell, D. R. Korber, and H. M. Lappin-Scott, "Microbial biofilms," Annual Review of Microbiology, vol. 49, pp. 711-745, 1995. 
[33] M. L. Fernandez, J. A. Broadbent, G. K. Shooter, J. Malda, and Z. Upton, "Development of an enhanced proteomic method to detect prognostic and diagnostic markers of healing in chronic wound fluid," British Journal of Dermatology, vol. 158, no. 2, pp. 281-290, 2008.

[34] A. B. Wysocki, "Wound fluids and the pathogenesis of chronic wounds," Journal of Wound, Ostomy and Continence Nursing, vol. 23, no. 6, pp. 283-290, 1996.

[35] D. R. Yager and B. C. Nwomeh, "The proteolytic environment of chronic wounds," Wound Repair and Regeneration, vol. 7, no. 6, pp. 433-441, 1999.

[36] F. Grinnell and M. Zhu, "Fibronectin degradation in chronic wounds depends on the relative levels of elastase, $\alpha 1$-proteinase inhibitor, and $\alpha 2$-macroglobulin," Journal of Investigative Dermatology, vol. 106, no. 2, pp. 335-341, 1996.

[37] V. Falanga, "Growth factors and chronic wounds: the need to understand the microenvironment," Journal of Dermatology, vol. 19, no. 11, pp. 667-672, 1992.

[38] H. Trøstrup, R. Lundquist, L. H. Christensen et al., "S100A8/A9 deficiency in nonhealing venous leg ulcers uncovered by multiplexed antibody microarray profiling," British Journal of Dermatology, vol. 165, no. 2, pp. 292-301, 2011.

[39] I. S. Thorey, J. Roth, J. Regenbogen et al., "The $\mathrm{Ca}^{2+}$-binding proteins S100A8 and S100A9 are encoded by novel injuryregulated genes," Journal of Biological Chemistry, vol. 276, no. 38, pp. 35818-35825, 2001.

[40] R. Zillmer, H. Trøstrup, T. Karlsmark, P. Ifversen, and M. S. Agren, "Duration of wound fluid secretion from chronic venous leg ulcers is critical for interleukin-lalpha, interleukin1beta, interleukin-8 levels and fibroblast activation," Archives of Dermatological Research, vol. 303, no. 8, pp. 601-606, 2011.

[41] B. Bucalo, W. H. Eaglstein, and V. Falanga, "Inhibition of cell proliferation by chronic wound fluid," Wound Repair and Regeneration, vol. 1, no. 3, pp. 181-186, 1993.

[42] P. Svedman, "Irrigation treatment of leg ulcers," The Lancet, vol. 2, no. 8349, pp. 532-534, 1983.

[43] G. S. Schultz, R. G. Sibbald, V. Falanga et al., "Wound bed preparation: a systematic approach to wound management," Wound Repair and Regeneration, vol. 11, supplement 1, pp. S1S28, 2003.

[44] S. J. Weiss, "Tissue destruction by neutrophils," New England Journal of Medicine, vol. 320, no. 6, pp. 365-376, 1989.

[45] L. E. Edsberg, J. T. Wyffels, M. S. Brogan, and K. M. Fries, "Analysis of the proteomic profile of chronic pressure ulcers," Wound Repair and Regeneration, vol. 20, no. 3, pp. 378-401, 2012.

[46] F. Werdin, M. Tennenhaus, H. E. Schaller, and H. O. Rennekampff, "Evidence-based management strategies for treatment of chronic wounds," Eplasty, vol. 9, article e19, 2009.

[47] F. E. Brolmann, D. T. Ubbink, E. A. Nelson, K. Munte, C. M. van der Horst, and H. Vermeulen, "Evidence-based decisions for local and systemic wound care," The British Journal of Surgery, vol. 99, no. 9, pp. 1172-1183, 2012.

[48] F. Gottrup and J. Apelqvist, "The challenge of using randomized trials in wound healing," British Journal of Surgery, vol. 97, no. 3, pp. 303-304, 2010.

[49] J. E. Jones and E. A. Nelson, "Skin grafting for venous leg ulcers," Cochrane Database of Systematic Reviews, no. 2, Article ID CD001737, 2007.
[50] W. H. Eaglstein and V. Falanga, "Tissue engineering and the development of Apligraf, a human skin equivalent," Cutis; Cutaneous Medicine for the Practitioner, vol. 62, no. 1, supplement, pp. 1-8, 1998.

[51] M. S. Gohel, J. R. Barwell, M. Taylor et al., "Long term results of compression therapy alone versus compression plus surgery in chronic venous ulceration (ESCHAR): randomised controlled trial," British Medical Journal, vol. 335, no. 7610, pp. 83-87, 2007.

[52] P. Kranke, M. Bennett, I. Roeckl-Wiedmann, and S. Debus, "Hyperbaric oxygen therapy for chronic wounds," Cochrane Database of Systematic Reviews, no. 2, Article ID CD004123, 2004.

[53] M. Cruciani, B. A. Lipsky, C. Mengoli, and F. de Lalla, "Granulocyte-colony stimulating factors as adjunctive therapy for diabetic foot infections," Cochrane Database of Systematic Reviews, no. 3, Article ID CD006810, 2009.

[54] F. Gottrup and B. Jorgensen, "Maggot debridement: an alternative method for debridement," Eplasty, vol. 11, article e33, 2011.

[55] L. Gilead, K. Y. Mumcuoglu, and A. Ingber, "The use of maggot debridement therapy in the treatment of chronic wounds in hospitalised and ambulatory patients," Journal of Wound Care, vol. 21, no. 2, pp. 78, 80, 82-85, 2012.

[56] F. Gottrup and T. Karlsmark, "Current management of wound healing," Giornale Italiano di Dermatologia e Venereologia, vol. 144, no. 3, pp. 217-228, 2009.

[57] S. J. Palfreyman, E. A. Nelson, R. Lochiel, and J. A. Michaels, "Dressings for healing venous leg ulcers," Cochrane Database of Systematic Reviews, vol. 3, Article ID CD001103, 2006.

[58] H. Vermeulen, J. M. van Hattem, M. N. Storm-Versloot, and D. T. Ubbink, "Topical silver for treating infected wounds," Cochrane Database of Systematic Reviews, no. 1, Article ID CD005486, 2007.

[59] J. L. Richard, C. Parer-Richard, J. P. Daures et al., "Effect of topical basic fibroblast growth factor on the healing of chronic diabetic neuropathic ulcer of the foot: a pilot, randomized, double-blind, placebo-controlled study," Diabetes Care, vol. 18, no. 1, pp. 64-69, 1995.

[60] V. Falanga, W. H. Eaglstein, B. Bucalo, M. H. Katz, B. Harris, and P. Carson, "Topical use of human recombinant epidermal growth factor (h-EGF) in venous ulcers," Journal of Dermatologic Surgery and Oncology, vol. 18, no. 7, pp. 604-606, 1992.

[61] S. M. Chen, S. I. Ward, O. O. Olutoye, R. F. Diegelmann, and I. K. Cohen, "Ability of chronic wound fluids to degrade peptide growth factors is associated with increased levels of elastase activity and diminished levels of proteinase inhibitors," Wound Repair and Regeneration, vol. 5, no. 1, pp. 23-32, 1997.

[62] M. C. Robson, "The role of growth factors in the healing of chronic wounds," Wound Repair and Regeneration, vol. 5, no. 1, pp. 12-17, 1997.

[63] P. A. M. Everts, J. T. A. Knape, G. Weibrich et al., "Platelet-rich plasma and platelet gel: a review," Journal of Extra-Corporeal Technology, vol. 38, no. 2, pp. 174-187, 2006.

[64] K. M. Lacci and A. Dardik, "Platelet-rich plasma: support for its use in wound healing," Yale Journal of Biology and Medicine, vol. 83, no. 1, pp. 1-9, 2010.

[65] T. M. Bielecki, T. S. Gazdzik, J. Arendt, T. Szczepanski, W. Król, and T. Wielkoszynski, "Antibacterial effect of autologous platelet gel enriched with growth factors and other active substances: an in vitro study," Journal of Bone and Joint Surgery $B$, vol. 89, no. 3, pp. 417-420, 2007. 
[66] D. J. Margolis, T. Crombleholme, and M. Herlyn, "Clinical protocol: phase I trial to evaluate the safety of H5.020CMV.PDGFB for the treatment of a diabetic insensate foot ulcer," Wound Repair and Regeneration, vol. 8, no. 6, pp. 480-493, 2000.

[67] P. J. Kim and J. S. Steinberg, "Wound care: biofilm and its impact on the latest treatment modalities for ulcerations of the diabetic foot," Seminars in Vascular Surgery, vol. 25, no. 2, pp. 70-74, 2012.

[68] B. Jorgensen, T. Karlsmark, H. Vogensen, L. Haase, and R. Lundquist, "A pilot study to evaluate the safety and clinical performance of Leucopatch, an autologous, additive-free, plateletrich fibrin for the treatment of recalcitrant chronic wounds," The International Journal of Lower Extremity Wounds, vol. 10, no. 4, pp. 218-223, 2011.

[69] S. M. O’Connell, T. Impeduglia, K. Hessler, X. J. Wang, R. J. Carroll, and H. Dardik, "Autologous platelet-rich fibrin matrix as cell therapy in the healing of chronic lower-extremity ulcers," Wound Repair and Regeneration, vol. 16, no. 6, pp. 749-756, 2008.

[70] W. C. Krupski, L. M. Reilly, S. Perez, K. M. Moss, P. A. Crombleholme, and J. H. Rapp, "A prospective randomized trial of autologous platelet-derived wound healing factors for treatment of chronic nonhealing wounds: a preliminary report," Journal of Vascular Surgery, vol. 14, no. 4, pp. 526-536, 1991.

[71] J. Cha and V. Falanga, "Stem cells in cutaneous wound healing," Clinics in Dermatology, vol. 25, no. 1, pp. 73-78, 2007.

[72] D. M. Castilla, Z. J. Liu, R. Tian, Y. Li, A. S. Livingstone, and O. C. Velazquez, "A novel autologous cell-based therapy to promote diabetic wound healing," Annals of Surgery, vol. 256, no. 4, pp. 560-572, 2012.

[73] N. M. Argolo Neto, R. J. Del Carlo, B. S. Monteiro et al., "Role of autologous mesenchymal stem cells associated with plateletrich plasma on healing of cutaneous wounds in diabetic mice," Clinical and Experimental Dermatology, vol. 37, no. 5, pp. 544553, 2012.

[74] A. Nather, S. B. Chionh, A. Y. Y. Han, P. P. L. Chan, and A. Nambiar, "Effectiveness of vacuum-assisted closure (VAC) therapy in the healing of chronic diabetic foot ulcers," Annals of the Academy of Medicine Singapore, vol. 39, no. 5, pp. 353-358, 2010.

[75] C. M. Mouës, F. Heule, and S. E. R. Hovius, "A review of topical negative pressure therapy in wound healing: sufficient evidence?" American Journal of Surgery, vol. 201, no. 4, pp. 544556, 2011.

[76] D. T. Ubbink, S. J. Westerbos, E. A. Nelson, and H. Vermeulen, "A systematic review of topical negative pressure therapy for acute and chronic wounds," British Journal of Surgery, vol. 95, no. 6, pp. 685-692, 2008.

[77] N. A. Cullum, D. Al-Kurdi, and S. E. Bell-Syer, "Therapeutic ultrasound for venous leg ulcers," Cochrane Database of Systematic Reviews, vol. 6, Article ID CD001180, 2010.

[78] D. Al-Kurdi, S. E. Bell-Syer, and K. Flemming, "Therapeutic ultrasound for venous leg ulcers," Cochrane Database of Systematic Reviews, no. 1, Article ID CD001180, 2008.

[79] K. A. Flemming, N. A. Cullum, and E. A. Nelson, "A systematic review of laser therapy for venous leg ulcers," Journal of Wound Care, vol. 8, no. 3, pp. 111-114, 1999.

[80] H. Anwar, "Association of a $38 \mathrm{kDa}$ bovine serum protein with the outer membrane of Bordetella pertussis," FEMS Microbiology Letters, vol. 95, no. 3, pp. 305-309, 1990.

[81] S. M. Moskowitz, J. M. Foster, J. Emerson, and J. L. Burns, "Clinically feasible biofilm susceptibility assay for isolates of
Pseudomonas aeruginosa from patients with cystic fibrosis," Journal of Clinical Microbiology, vol. 42, no. 5, pp. 1915-1922, 2004.

[82] U. Furustrand Tafin, I. Majic, C. Zalila Belkhodja et al., "Gentamicin improves the activities of daptomycin and vancomycin against Enterococcus faecalis in vitro and in an experimental foreign-body infection model," Antimicrobial Agents and Chemotherapy, vol. 55, no. 10, pp. 4821-4827, 2011.

[83] W. Hengzhuang, H. Wu, O. Ciofu, Z. Song, and N. Hoiby, "Pharmacokinetics/pharmacodynamics of colistin and imipenem on mucoid and nonmucoid Pseudomonas aeruginosa biofilms," Antimicrobial Agents and Chemotherapy, vol. 55, no. 9, pp. 4469-4474, 2011.

[84] W. Hengzhuang, H. Wu, O. Ciofu, Z. Song, and N. Hoiby, "In vivo pharmacokinetics/pharmacodynamics of colistin and imipenem in Pseudomonas aeruginosa biofilm infection," Antimicrobial Agents and Chemotherapy, vol. 56, no. 5, pp. 2683-2690, 2012.

[85] W. Zimmerli and C. Moser, "Pathogenesis and treatment concepts of orthopaedic biofilm infections," FEMS Immunology and Medical Microbiology, vol. 65, no. 2, pp. 158-168, 2012.

[86] O. C. El Helou, E. F. Berbari, B. D. Lahr et al., "Efficacy and safety of rifampin containing regimen for staphylococcal prosthetic joint infections treated with debridement and retention," European Journal of Clinical Microbiology and Infectious Diseases, vol. 29, no. 8, pp. 961-967, 2010.

[87] N. Høiby, T. Bjarnsholt, M. Givskov, S. Molin, and O. Ciofu, "Antibiotic resistance of bacterial biofilms," International Journal of Antimicrobial Agents, vol. 35, no. 4, pp. 322-332, 2010.

[88] G. Herrmann, L. Yang, H. Wu et al., "Colistin-tobramycin combinations are superior to monotherapy concerning the killing of biofilm Pseudomonas aeruginosa," Journal of Infectious Diseases, vol. 202, no. 10, pp. 1585-1592, 2010.

[89] S. J. Pamp, M. Gjermansen, H. K. Johansen, and T. TolkerNielsen, "Tolerance to the antimicrobial peptide colistin in Pseudomonas aeruginosa biofilms is linked to metabolically active cells, and depends on the pmr and mexAB-oprM genes," Molecular Microbiology, vol. 68, no. 1, pp. 223-240, 2008.

[90] N. Høiby, O. Ciofu, H. K. Johansen et al., “The clinical impact of bacterial biofilms," International Journal of Oral Science, vol. 3, no. 2, pp. 55-65, 2011.

[91] S. E. Dowd, R. D. Wolcott, J. Kennedy, C. Jones, and S. B. Cox, "Molecular diagnostics and personalised medicine in wound care: assessment of outcomes," Journal of Wound Care, vol. 20, no. 5, pp. 232-239, 2011. 


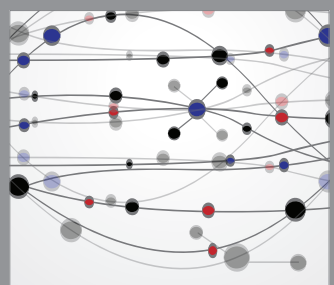

The Scientific World Journal
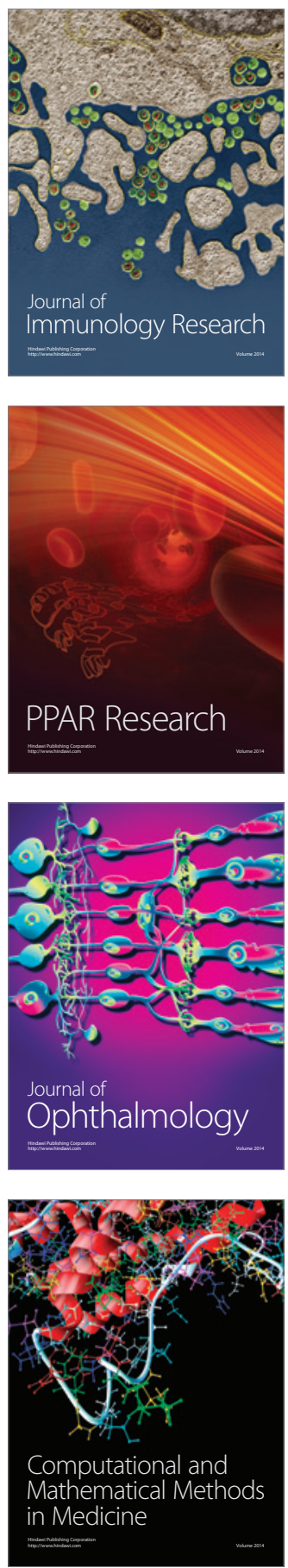

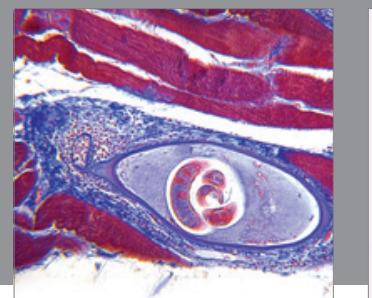

Gastroenterology

Research and Practice
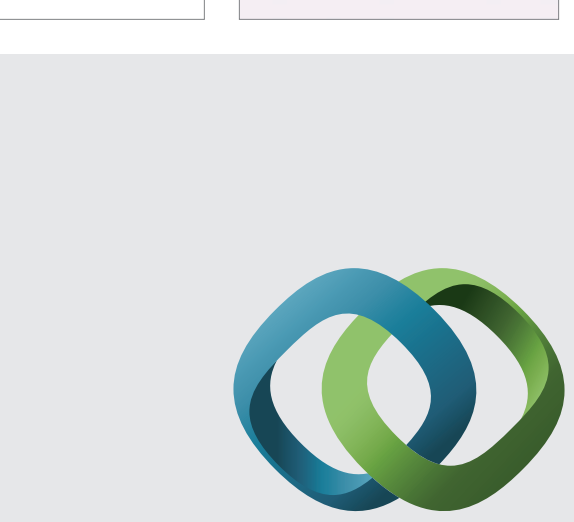

\section{Hindawi}

Submit your manuscripts at

http://www.hindawi.com
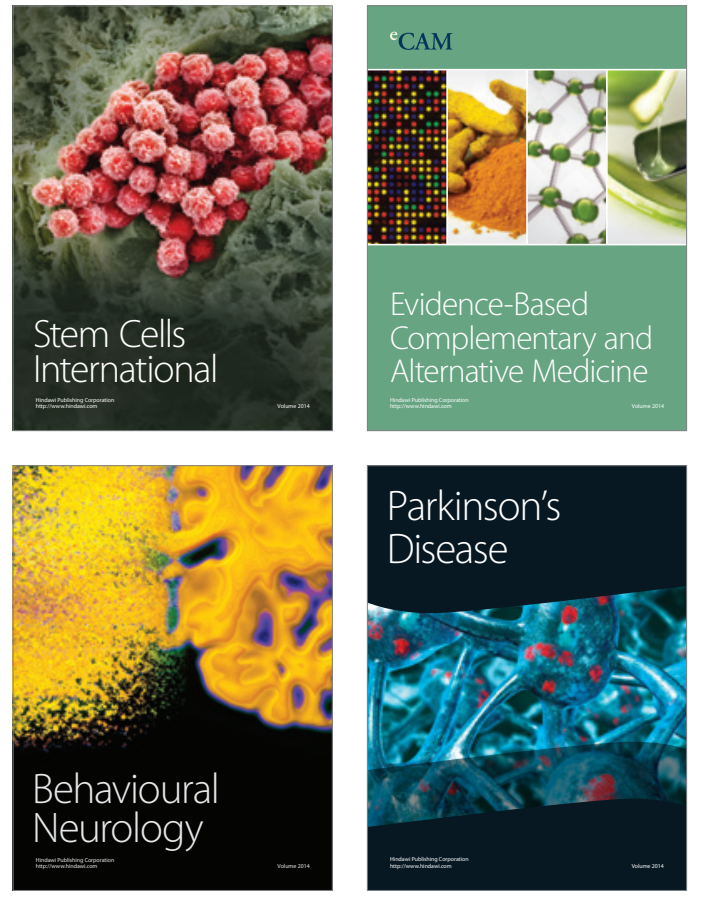
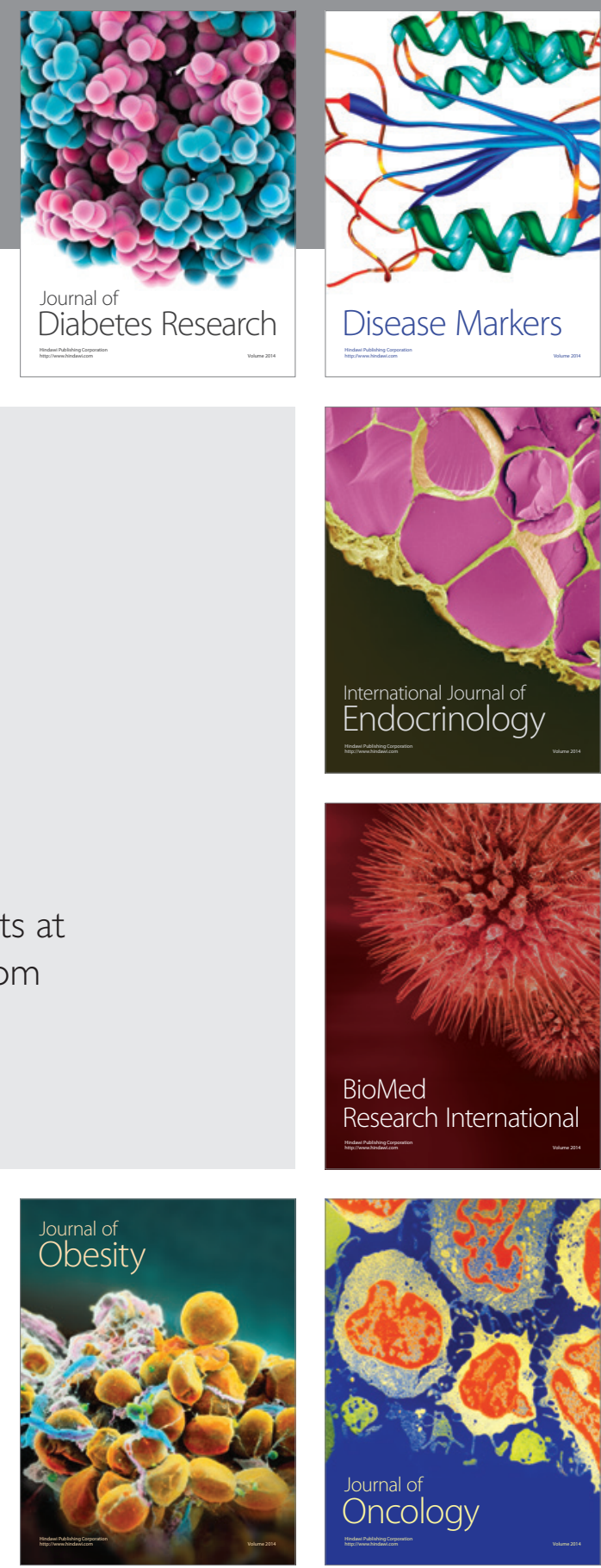

Disease Markers
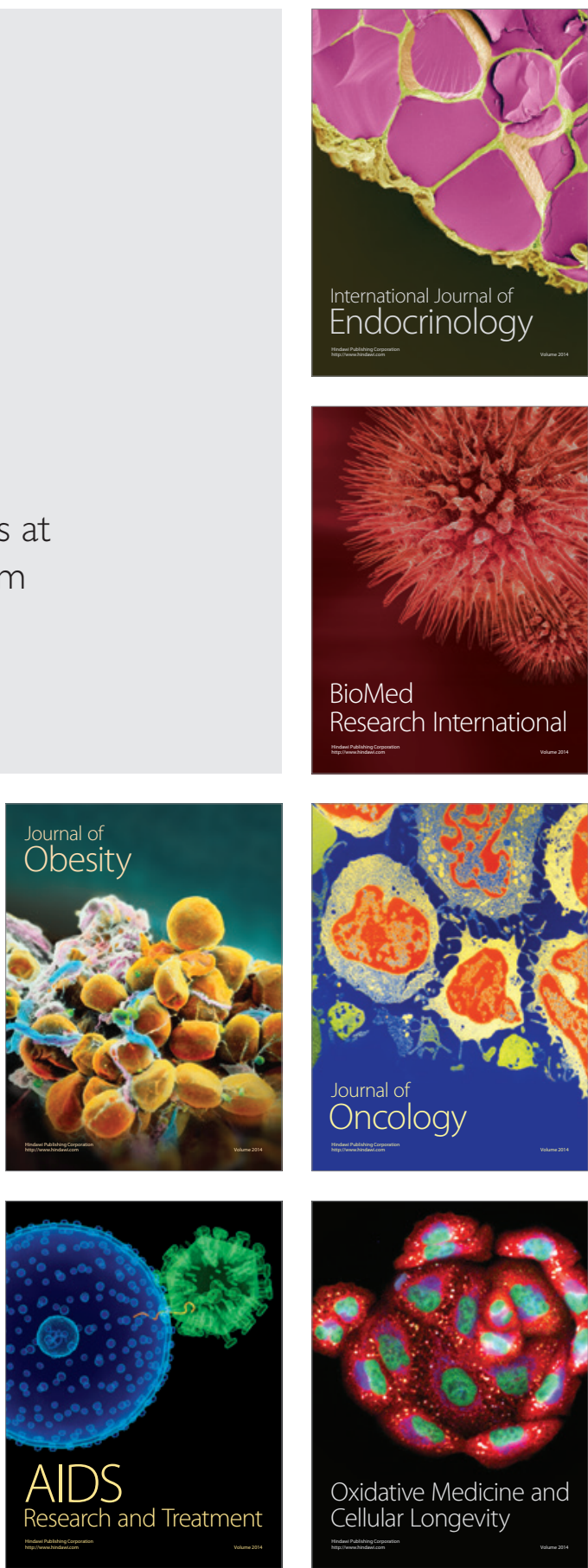